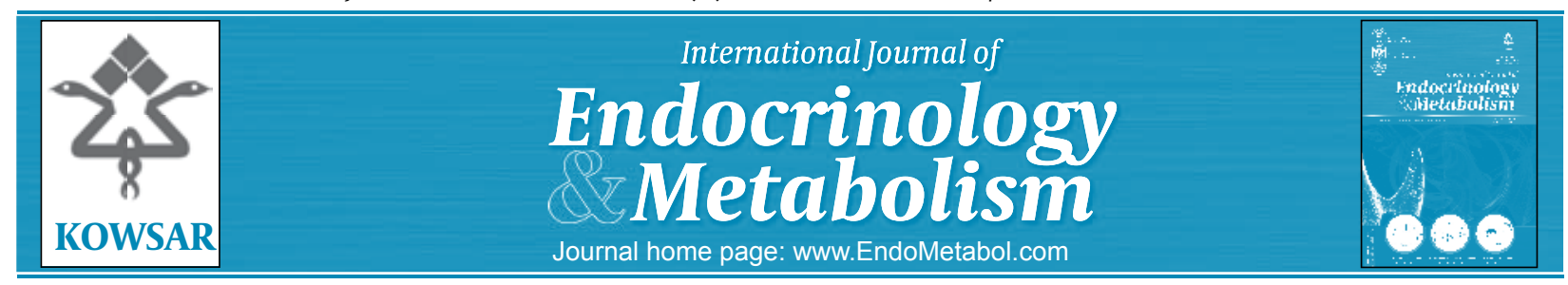

\title{
Glucose Tolerance Evaluation in Graves Patients Treated with Methimazole and Radioiodine
}

\author{
Eijun Nishihara ${ }^{1}$, Masafumi Koga ${ }^{2^{*}}$ \\ ${ }^{1}$ Department of Internal Medicine, Kuma Hospital, Hyogo, Japan \\ ${ }^{2}$ Department of Internal Medicine, Kinki Central Hospital, Hyogo, Japan
}

A R T I C L E I N F O

Article type:

Letter to Editor

Article history:

Received: 20 Aug 2011

Revised: 27 Aug 2011

Accepted: 09 Sep 2011

Keywords:

Graves's Patients

Radioactive Iodine

\section{Dear Editor,}

The manuscript, "Evaluation of Glucose Tolerance in Methimazole and Radioiodine Treated Graves' Patients," by Kiani J et al. (1) compared glucose tolerance in Graves' disease patients treated with methimazole to those treated with radioiodine. The results indicated that radioiodine therapy had no adverse effects on glucose tolerance or insulin resistance. This study has an impact on whether particular attention should be paid to diabetes mellitus in patients after radioiodine therapy. The conclusion is reasonable, but the design of this study raises several questions concerning glucose tolerance, beyond simply damage to the pancreas caused by radioiodine.

First, not only the present state of thyroid function but also its functional changes throughout each treatment for Graves' disease may affect glucose tolerance. Without knowing the patient's glucose tolerance before receiving radioiodine, the exact change is difficult to evaluate in each individual. Second, the level of sodium

*Corresponding author: Masafumi Koga, Department of Internal Medicine, Kinki Central Hospital, 3-1 Kuruma-zuka, Itami, Hyogo 664-8533, Japan. Tel: +81-727813712, Fax:+81-727791567, E-mail: koga_m@kich.itami.hyogo.jp

DOI:10.5812/Kowsar.1726913X.2365

Copyright $\odot 2011$ Kowsar M.P.Co. All rights reserved.

- Please cite this paper as:

Nishihara E, Koga M. Glucose Tolerance Evaluation in Graves Patients Treated with Methimazole and Radioiodine. Int J Endocrinol Metab. 2011;9(4):377-8. DOI:10.5812/Kowsar.1726913X.2365

Copyright @ 2011 Kowsar M. P. Co. All rights reserved.

iodide symporter (NIS) expression in the pancreas remains controversial. One report demonstrated strong NIS immunoreactivity in pancreatic islet cells (2). Another report, however, did not find any evidence of NIS immunoreactivity in the pancreas (3). This discrepancy may be caused by the anti-NIS antibodies used in each study. Regardless, in both studies, the NIS expression level in the pancreas was quite low compared to the level in the thyroid gland. Given that TSH stimulates radioiodine uptake in thyroid tissue but not in extrathyroidal tissue because of the absence of TSH receptors, radioiodine accumulation in the pancreas is inhibited in the presence of the thyroid gland. To decrease this interference with radioiodine uptake, more efficient radioiodine accumulation in the pancreas may be one way to administer high doses of radioiodine as pointed out by the authors. Alternatively, thyroid-cancer patients who undergo a total thyroidectomy followed by remnant ablation may be good candidates for evaluation of glucose tolerance in patients after radioiodine therapy (1). In this situation, physiological accumulation of radioiodine can be identified by scintigraphy, and, when present, suggests possible subsequent damage in the tissues. Although it is rare to detect clear radioiodine accumulation in the pancreas of thyroid-cancer patients after radioiodine therapy or development 
of diabetes mellitus in patients, future studies should still examine this issue because minor side effects are not well understood.

\section{Financial Disclosure}

None declared.

\section{References}

1. Kiani J, Yusefi V, Tohidi M, Mehrabi Y, Azizi F. Evaluation of glucose tolerance in methimazole and Radioiodine treated Graves' patients. Int J Endocrinol Metab. 2010;8(3):132-7.

2. Spitzweg C, Joba W, Schriever K, Goellner JR, Morris JC, Heufelder AE. Analysis of human sodium iodide symporter immunoreactivity in human exocrine glands. J Clin Endocrinol Metab. 1999;84(11):4178-84.

3. Vayre L, Sabourin JC, Caillou B, Ducreux M, Schlumberger M, Bidart JM. Immunohistochemical analysis of $\mathrm{Na}+$ /I- symporter distribution in human extra-thyroidal tissues. Eur J Endocrinol. 1999;141(4):382-6. 